\title{
Feminização do magistério na rede municipal de ensino de Sorocaba sob a perspectiva dos professores
}

\section{Feminization of teaching in the Sorocaba municipal school system under the teacher's perspective}

\section{Feminización de la enseñanza en la red educativa de Sorocaba bajo la perspectiva de los maestros}

\author{
Rafaela de Souza Lima ${ }^{1}$ \\ João Henrique da Silva²
}

DOI: http://dx.doi.org/10.20435/serie-estudos.v26i57.1414

\begin{abstract}
Resumo: A pesquisa teve como objetivo investigar o fenômeno da feminização do magistério na cidade de Sorocaba, SP, bem como as perspectivas da construção de gênero das professoras da rede de ensino, buscando compreender as influências de tais aspectos em seu trabalho pedagógico na educação infantil. Trata-se de uma pesquisa qualitativa, por meio de pesquisa bibliográfica, questionários semiabertos e entrevista semiestruturada. Aplicou-se o questionário para nove docentes, sendo que duas professoras foram entrevistadas. Os resultados da pesquisa demonstram que à maioria dos profissionais são mulheres, ou seja, oito professoras, sendo então, cinco casadas com pelo menos dois filhos. Sete possuem formação inicial em Pedagogia em instituições privadas e somente duas, são graduadas em universidades públicas. Há apenas um professor do sexo masculino, formado numa instituição privada, casado e com dois filhos. No que concerne ao nível de formação continuada, todos professores possuem pelo menos duas pós-graduações, cursadas também em instituições privadas, com exceção de apenas uma professora que possui mestrado e doutorado em educação. Portanto, o perfil dos participantes da pesquisa é semelhante entre si, o que evidencia a feminização do magistério na educação infantil, principalmente, porque decorrem da experiência familiar e das concepções de gênero, isto é, ser professor da educação infantil corresponde às representações sociais de ser mulher, mãe, afetuosa e cuidadora.
\end{abstract}

Palavras-chave: gênero e educação; relações de gênero; educação infantil.

Abstract: The research has the purpose of look into the phenomenon of feminization of teaching in Sorocaba, SP city, as well as the perspectives of gender construction in those women, looking for understand the levering in these pedagogical aspects in their pedagogical work in childhood

\footnotetext{
${ }^{1}$ Universidade Paulista (UNIP), Sorocaba, São Paulo, Brasil.

2 Universidade Tuiuti do Paraná (UTP), Curitiba, Brasil.
} 
education. It is a qualitative research, trough bibliographic search, half-open questionnaires and semi-structured interview. The questionnaires were applied to nine different teachers, whereby two of them were interviewed. The research results showed that most of teaching professional are women, 8 women teachers and five of them are married and have, at least, two children. Seven of them studied Pedagogy in private universities and only two of them in public universities. There is only a man teacher, married and has two children. Regarding the educational level, all of them have at least two undergraduate programs in there resumé, in private universities, except for one-woman teacher, who has master's degree and PhD in education. Therefore, the participant's profile is similar between all of them, which shows the feminization of teaching in early childhood education, mostly because arise from family's experiences and gender conceptions, what means that being a childhood teacher match with social representation of being a woman, mother, affectionate and caretaker.

Keywords: gender and education; gender relations; childhood education.

Resumen: La investigación tuvo como objetivo analizar el fenómeno de la feminización de la enseñanza en la ciudad de Sorocaba, SP, así como las perspectivas de la construcción de género de las profesoras de la red educativa, buscando entender las influencias de estos aspectos en su trabajo pedagógico en la educación infantil. Esta es una encuesta cualitativa a través de la búsqueda bibliográfica, cuestionarios semiabiertos y entrevistas semiestructuradas. Se aplicó el cuestionario a nueve maestros y dos de estos profesores fueran entrevistadas. Los resultados de la investigación muestran que la mayoría de los profesionales son mujeres, es decir, ocho profesoras, cinco son casadas con por lo menos dos hijos. Siete tienen formación inicial en pedagogía hecha en instituciones privadas y solo dos son graduadas en universidades públicas. Hay solo un profesor de lo sexo masculino, formado de la universidad particular, casado y con dos hijos. Con respecto a la educación continua, todos los maestros tienen por lo menos dos grados posteriores, también cursados en instituciones privadas, a excepción de una docente con maestría y doctorado en educación. Por lo tanto, lo perfil de los participantes de la investigación es similar en un al otro, evidenciando la feminización de la enseñanza en la educación infantil, principalmente por que proviene de la experiencia familiar y de las concepciones de género, es decir, ser profesor en la educación infantil corresponde a las representaciones sociales de ser mujer, madre, cariñosa y cuidadora.

Palabras clave: género y educación; relaciones de género; educación infantil.

\section{INTRODUÇÃO}

O tema deste artigo é a feminização do magistério visto como um fenômeno de cunho histórico e social, que busca compreender e explicar a inserção da mulher para a docência, especialmente para o magistério (SÁ; ROSA, 2004; RABELO; MARTINS, 2010). Sob a ótica de uma perspectiva de gênero, configurada na construção histórica do que é ser mulher na sociedade, esta pesquisa discute as características evocadas como femininas - mãe, cuidadora, educadora, apaziguadora etc. -, estendendo-se ao seu ingresso na busca por profissionalização no professorado e como tais aspectos refletem na educação. 
Com a abertura da docência às mulheres, suas qualidades profissionais se tornaram limitadas, pois o que era realmente valorizado eram suas características femininas, como um suposto "dom" de mediar o comportamento emocional e moral das crianças. Esse "dom", portanto, explica-se pelo poder da mulher de gerar um indivíduo, "consequente função materna", de cuidar e educar crianças. Para compreender tais informações, deve-se estar atento sob um olhar crítico e reflexivo para perceber que estes fatos históricos e perpetuados são objetos de estudos, pois apresentam informações veladas. Ou seja, não se trata somente de termos da ascensão da mulher ao mercado de trabalho, mas sim de uma perspectiva social da construção do gênero feminino difundido com o olhar maternal da educação infantil (LOURO 2014; DIAS; CRUZ, 2015; PRÁ; CEGATTI, 2016; OLIVEIRA, 2011).

Louro (2014) afirma que o ser masculino e o feminino são construídos socialmente, e, dentro de uma determinada sociedade, recebem influências de outros grupos, sejam eles étnicos, sejam eles religiosos, raciais ou de classe que também constituem tais aspectos. Trata-se, então, de uma relação de poder que é estabelecida desde os primórdios e, infelizmente, perdura até o dia de hoje. A autora ainda postula que atribuir ao gênero um caráter inteiramente social não anula que a sua construção se dá sob a ótica de corpos sexuados, mas ressalta que suas características sociais e históricas são concebidas sobre aspectos biológicos (LOURO, 2014). Então, "[...] o conceito de gênero pretende se referir ao modo como as características sexuais são compreendidas e representadas ou, então, como são trazidas para a prática social e tornadas parte do processo histórico" (LOURO, 2014, p. 26).

Como ensina Louro (2014), a construção dos gêneros significa as representações sociais dentro da sociedade, pautadas em aspectos biológicos, e, como resultado, crenças disseminadas pelo senso comum ganham cada vez mais espaço. Então, isso pode nos levar a questionar que as mulheres, por sua função "geradora", consequentemente, nasceram para ser mães? Ou melhor, ao adentrar na educação, prioritariamente na educação infantil, quais são suas características aclamadas? O perfil do professor da educação infantil é pautado na formação pedagógica ou no senso comum - seu suposto "dom" de acalentar crianças?

A partir dessas considerações, realizou-se uma pesquisa que partiu das seguintes problematizações: qual é o perfil dos professores da rede municipal de ensino de Sorocaba que atuam na educação infantil? Quais são as características 
em termos de gênero, idade, formação inicial e continuada? Como os professores percebem seu trabalho pedagógico na educação infantil? Quais são as suas possibilidades e desafios na formação educacional de crianças?

Dessa forma, o objetivo da presente pesquisa foi investigar a feminização do magistério e as perspectivas das professoras da rede municipal de ensino de Sorocaba, buscando compreender o que é ser mulher na contemporaneidade e como isso reflete na sua prática pedagógica na relação cuidar e educar.

\section{MÉTODO}

A presente pesquisa buscou analisar o perfil dos professores da rede de ensino de Sorocaba, seu trabalho na educação infantil e suas concepções sobre as formações dos sujeitos. Para tanto, foram mobilizados recursos qualitativos, utilizando dados propiciados por questionários e, posteriormente, a entrevista semiestruturada.

A abordagem qualitativa tem como principal ação realizar

[...] descrições detalhadas de situações, eventos, pessoas, interações e comportamentos que são: descrições detalhadas e comportamentos que são observáveis, incorporando a voz dos participantes, suas experiências, atitudes, crenças, pensamentos e reflexões, tal e qual são expressas por eles mesmos. (SERRANO, 1994a, p. 46 apud ESTEBAN, 2010, p. 125).

A pesquisa qualitativa possibilita compreender a experiência humana, na sua complexidade, e explicitar a lógica dos contextos em que estão inseridos os sujeitos e os grupos (MINAYO; ASSIS; SOUZA, 2005, p. 90). Assim sendo, a escola que serviu como campo para a pesquisa é uma unidade da rede municipal de ensino e está localizada na cidade de Sorocaba, recebendo o nome de "E.M. Antônio Carlos" (nome fictício), situada no bairro Vila Angélica. Ao ser submetido ao Comitê de Ética em Pesquisa em Seres Humanos, o projeto de pesquisa foi aprovado por este e indicado pelo número do parecer: 3.065.981, ano de 2018.

A "E.M. Antônio Carlos" é uma construção predial nova, contabilizando somente três anos. O ambiente nos revela um ar leve, arejado, demonstrando a identidade de cada funcionário que está presente ali. Atende crianças no período da manhã e da tarde, desde a pré-escola até o 5o ano do ensino fundamental I, contando com 19 professores. 
Os participantes da pesquisa foram nove professores da rede de ensino municipal, que responderam ao questionário fechado, o qual contém questões que identificam o perfil dos entrevistados. A justificativa para a escolha desse instrumento de coleta de dados consistiu na possibilidade de atingir os objetivos da pesquisa dentro do prazo exequível. Os dados deram a oportunidade de formulação de tabelas e gráficos para a elucidação da temática estudada (CHAER; DINIZ; RIBEIRO, 2011, p. 251).

De posse dos dados dos questionários, foram construídas as seguintes categorias para organizar e realizar o tratamento dos dados: configuração familiar (situação civil, idade, sexo, quantidade de filhos), perfil de formação (curso[s] de formação inicial, instituição de ensino superior, ano de conclusão, curso[s] de formação continuada/pós-graduação, cursos complementares), tempo de experiência na docência (educação básica e educação infantil).

Posteriormente, foram selecionadas duas professoras desta unidade para a entrevista, obedecendo aos seguintes critérios: gênero feminino, formação inicial em pedagogia, tempo de atuação igual ou superior a cinco anos na rede municipal, idade acima de 20 anos. Tais critérios possibilitam a imersão de informações de forma mais livre, propiciando o levantamento de novas hipóteses a partir das respostas das entrevistadas.

De acordo com Manzini (2004), a técnica da entrevista semiestruturada tem como característica questionamentos básicos que são apoiados em teorias e hipóteses que se relacionam ao tema da pesquisa. Os questionamentos dariam frutos a novas possibilidades oriundas a partir das respostas dos informantes. As entrevistas foram transcritas em sua íntegra e, posteriormente, trabalhou-se com as categorias: gênero e educação, condições do trabalho docente, ambiente familiar, relação cuidar e educar na educação infantil.

Utilizou-se a técnica de triangulação de dados (MINAYO; ASSIS; SOUZA, 2005), o que permitiu confrontar as discussões da bibliografia; as legislações pertinentes; os dados coletados por meio dos questionários e das entrevistas; e o referencial teórico em Bourdieu. A triangulação de dados fez-se necessária ao analisar as respostas das entrevistadas e com rigorosidade, classificá-los de uma forma sistemática.

O referencial teórico pauta-se em Pierre Bourdieu, um importante sociólogo francês e autor do livro "A dominação Masculina: a condição feminina e a violência 
simbólica" (1998), o qual serviu como respaldo teórico para analisar questões relacionadas a gênero ao longo deste trabalho.

Bourdieu (2019) alega que tudo que acontece em sociedade é histórico e socialmente criado, ou seja, nada parte de uma questão natural. E isso acaba se tornando tarefa de uma categoria dominante, fazendo com que os dominados percebam determinados fatores como "reais", influenciando principalmente no constituir-se homem e mulher na sociedade.

Como estamos incluídos, homem ou mulher, no próprio objeto que nos esforçamos por aprender, incorporamos, sob a forma de esquemas inconscientes de percepção e de apreciação, as estruturas históricas de ordem masculina; arriscamo-nos, pois, a recorrer, para pensar a pensar a dominação masculina, a modos de pensamento que são eles próprios produto da dominação. (BOURDIEU, 2019, p. 17).

Bourdieu (2019) diz que a relação de dominação masculina não se dá somente em relações de marido e mulher, mas sim em aparelhos criados pelo Estado que perpetuam tais desigualdades, como instituições religiosas e escolas. A força da ordem masculina se evidencia no fato de que ela dispensa justificação: a visão androcêntrica impõe-se como neutra e não tem necessidade de se enunciar em discursos que visem a legitimá-la (BOURDIEU, 2019, p. 18). Ou seja, a questão da neutralidade masculina evidencia poder. Enquanto o feminino é usado como parâmetro: pouco feminino, muito feminino ou não feminino.

A ordem social funciona como uma imensa máquina simbólica que tende a ratificar a dominação masculina sobre a qual se alicerça: é a divisão social do trabalho, distribuição bastante estrita das atividades atribuídas a cada um dos dois sexos, de seu local, seu momento, seus instrumentos; é a estrutura do espaço, opondo o lugar de assembleia ou de mercado, reservados aos homens, e a casa, reservada às mulheres; ou, no interior desta, entre a parte masculina, com o salão, e a parte feminina, com o estábulo, a água e os vegetais [...]. (BOURDIEU, 2019, p. 18).

O sociólogo ainda fundamenta que os corpos são vistos como sexuados e que as divisões na sociedade, principalmente no trabalho, fundamentam-se em órgãos sexuais.

O mundo social constrói o corpo como realidade sexuada e como depositário de princípios de visão e de divisão sexualizantes. Esse programa social de percepção incorporada aplica-se a todas as coisas do mundo e, antes 
de tudo, ao próprio corpo, em sua realidade biológica: é ele que constrói a diferença entre os sexos biológicos, conformando-a aos princípios de uma visão mítica do mundo, enraizada na relação arbitrária de dominação dos homens sobre as mulheres, ela mesma inscrita, com a divisão do trabalho, na realidade da ordem social. (BOURDIEU, 2019, p. 26).

Ou seja, órgãos sexuais serão responsáveis pela divisão e ocupações de homens e mulheres em tais espaços. A anatomia sexual destes indivíduos determinará quais serão suas atividades. Homens e sua virilidade estritamente ligada ao seu falo e questões voltadas a sua prática fecundante, de ereção e crescimento da sua honra (BOURDIEU, 2019).

Por esta característica, Bourdieu (2019) alega que a relação de dominação acontece ao mesmo tempo de forma objetiva, e com suas divisões sexuais, e subjetiva, que, segundo a organização dessa objetividade, ordena a visão das divisões objetivas, isto é, as organizações sociais como o trabalho.

Diante de tais aspectos, Bourdieu (2019) ensina que, ao analisar características biológicas, são elas que determinarão como os indivíduos enxergarão a si e ao outro e, assim, agirão em sociedade. Os homens, fortes, habilidosos, inteligentes, em esferas públicas, devido a sua anatomia ereta, que aparenta e cresce ao longo da sua vida, atribuindo-lhe poder e honra. As mulheres, por exemplo, com características sexuais fechadas, sagradas, terão seu espaço em esfera privada, nos lares, nas famílias, e, com suas características sensíveis e dóceis, caberão em ambientes nos quais seus cuidados se farão necessários, como a atuação com crianças, em escolas e, principalmente, nas etapas da educação infantil, evidenciando o fenômeno da feminização do magistério, analisado ao longo desta pesquisa.

\section{RESULTADOS E DISCUSSÕES}

A pesquisa de gênero no ambiente escolar é de fundamental importância, a fim de promover práticas que objetivem a desconstrução de estereótipos e marcas históricas sobre ser homem e mulher na sociedade; consequentemente, tais práticas afetam diretamente a vida das crianças. E a escola, como espaço de apropriação dos saberes, tem o papel de formar o aluno em seu sentido integral, ou seja, desenvolver seu lado humano, psicológico, social e, principalmente, livre, para ser o que quiser. Em aspecto profissional, ressaltar que características atri- 
buídas ao feminino não são exigências do professorado, mas o que é primordial é sua formação profissional, fornecendo espaço, inclusive, para homens.

Sorocaba, entre outras cidades do estado de São Paulo, ocupa a 6a posição no ranking de matrículas em escolas públicas municipais, no âmbito da educação infantil, totalizando 12.334, segundo dados do IBGE de 2017. E, em âmbito docente, ainda na educação infantil, Sorocaba ocupa a 12a colocação, quantificando 426 professores (IBGE, 2017). Nota-se uma defasagem nos dados apresentados, visto que não há uma especificação em termos de gênero.

Uma reportagem publicada pelo Cruzeiro do Sul, em 2018, jornal local da cidade de Sorocaba, trouxe dados sobre a presença masculina na docência e em ocupações ditas como "femininas".

Hoje em Sorocaba, na rede municipal de ensino, a proporção é de um homem lecionando na educação infantil para 40 mulheres no mesmo cargo. Ou seja, 2,4\% dos professores são homens. Já entre os auxiliares de educação, embora exista a disparidade, a diferença é menor, sendo de um homem para 14 mulheres na mesma função (o que representa 6,8\%). (PESSOA, 2018, s.p.).

A mesma reportagem nos traz dados que nos fazem refletir:

Segundo o Censo Escolar 2017, estudo oficial com os dados mais recentes da educação básica no Brasil, há hoje 575 mil docentes na educação infantil brasileira, sendo 554 mil mulheres e 21 mil homens. Quer dizer, para cada professor homem numa creche ou sala de pré-escola, há 26 mulheres. Em Sorocaba, são 2.219 professoras para 55 professores na educação infantil segundo dados da Secretaria de Educação (Sedu). (PESSOA, 2018, s.p.).

Tendo presente essa realidade, foram utilizados questionários fechados para identificar um perfil em comum entre professores de uma escola pública da rede municipal de ensino de Sorocaba. De modo geral, a equipe conta com 19 professores, que, de modo diversificado, atendem educação infantil e ensino fundamental I, e três integrantes da equipe gestora: diretor, vice-diretor e coordenadora pedagógica. Foi lançado o convite para que todos participassem, entretanto nove aceitaram responder. Os participantes foram identificados com nomes fictícios, para que fosse guardado o anonimato e a identidade dos participantes. Identificou-se que oito participantes são do gênero feminino e um do masculino, que chamaremos de Beto. A faixa etária de maior predominância é de 30-35 anos, categorizando quatro indivíduos: Beto, Maria, Marcela e Isabel; Ana Cláudia e Márcia, entre 36-40 anos; outros dois inseridos na categoria de 40-50 
anos; Fernanda e Juliana, em seguida; e, por fim, apenas uma pessoa com mais de 50 anos de idade, Antônia.

Em âmbito familiar, conforme o Quadro 1, nota-se que três professoras são casadas e com dois filhos, com idades bem diversificadas: 31 e 27 anos; 11 anos; cinco e um ano. E o único homem participante tem também dois filhos, com idade de nove e seis anos. Mas há exceções: uma docente é casada, porém sem filhos; e uma docente é solteira e sem filhos. Estão inseridas na categoria de divorciada, duas docentes: uma tem três filhos, com idade de 19, 17 anos e 14 anos; e a outra, dois, com idade de 21 e 18 anos; por fim, inserida numa união estável, está uma professora com apenas um filho, com idade de três anos.

Quadro 1 - Configuração familiar dos participantes do questionário

\begin{tabular}{|l|c|c|c|c|}
\hline \multicolumn{1}{|c|}{ Participante } & Situação civil & Sexo & Idade & $\begin{array}{c}\text { Filhos } \\
\text { (quantidade) }\end{array}$ \\
\hline Maria & Casada & Feminino & 35 anos & Dois \\
\hline Marisa & Solteira & Feminino & 30 anos & Não tem \\
\hline Isabel & Casada & Feminino & 30 anos & Dois \\
\hline Beto & Casado & Masculino & 34 anos & Dois \\
\hline Ana Cláudia & Casada & Feminino & 36 anos & Não tem \\
\hline Márcia & União estável & Feminino & 36 anos & Um, apenas \\
\hline Fernanda & Divorciada & Feminino & 40 anos & Dois \\
\hline Juliana & Divorciada & Feminino & 40 anos & Três \\
\hline Antônia & Casada & Feminino & + de 50 anos & Dois \\
\hline
\end{tabular}

Fonte: Dados de pesquisa (2019).

Verifica-se que 62,5\% dessas mulheres possuem uma experiência familiar e com filhos, ou seja, a maior parte das professoras é mãe e casada. Esse fenômeno corresponde à realidade nacional brasileira, conforme dados do Ministério da Educação/Instituto Nacional de Estudos e Pesquisas Educacionais Anísio Teixeira (MEC/INEP), que constatou que, em nível Brasil, 96,6\% dos professores da educação inicial são mulheres. Dessas professoras, 54,4\% tem menos de 40 anos. Apenas 1,8\% delas têm mais de 60 anos (BRASIL, 2017).

Aliás, chama atenção a idade que estes/as docentes têm. Com idades que se aproximam da fase do adulto médio, possuem um perfil que corresponde com a sua responsabilidade profissional e com a sua família. 
Quadro 2 - Perfil de formação dos participantes

\begin{tabular}{|c|c|c|c|c|c|}
\hline Participantes & Formação & Universidade & Ano & Pós-graduação & Cursos complementares \\
\hline Maria & Pedagogia & $\begin{array}{l}\text { Universidade } \\
\text { Paulista (UNIP) }\end{array}$ & 2005 & $\begin{array}{l}\text { Práticas educativas da Educação Infantil } \\
\text { (OSE/UIRAPURU- 2007). } \\
\text { Libras (Nobre Educacional - 2012) }\end{array}$ & $\begin{array}{l}\text { Programa Gestão de Excelência } \\
\text { (PGE) (Fund. Pitágoras - 2014). } \\
\text { Disciplinas especiais na Universida- } \\
\text { de Federal de São Carlos (UFSCar) } \\
\text { Sorocaba - } 2015 \text { e } 2017\end{array}$ \\
\hline Marisa & Pedagogia & $\begin{array}{l}\text { Faculdade } \\
\text { Uirapuru }\end{array}$ & 2010 & $\begin{array}{l}\text { Psicopedagogia - Faculdade Veris (2012) } \\
\text { Ludopedagogia e arte-educação - NEP (2017) }\end{array}$ & Não \\
\hline Isabel & Pedagogia & UNIP & 2007 & Direito Educacional - São Luís (2010) & Não \\
\hline Beto & Pedagogia & $\begin{array}{l}\text { Centro Universi- } \\
\text { tário Internacio- } \\
\text { nal (UNINTER) } \\
\end{array}$ & 2012 & $\begin{array}{l}\text { Alfabetização e Letramento - Faculdade da } \\
\text { Aldeia de Carapicuíba (FALC) }\end{array}$ & Não \\
\hline Ana Cláudia & Pedagogia & $\begin{array}{l}\text { Universidade } \\
\text { Estadual Paulista } \\
\text { "Júlio de Mesqui- } \\
\text { ta Filho" (UNESP) }\end{array}$ & 2011 & $\begin{array}{l}\text { Oferecida pela Prefeitura - (Faculdade } \\
\text { Pitágoras). } \\
\text { Mestrado e Doutorado em Educação } \\
\text { pela Universidade Estadual de Campinas } \\
\text { (UNICAMP). }\end{array}$ & $\begin{array}{l}\text { Orientação educacional e } \\
\text { Supervisão Educacional pela UNESP. }\end{array}$ \\
\hline Márcia & Pedagogia & $\begin{array}{l}\text { Universidade } \\
\text { de Sorocaba } \\
\text { (UNISO) }\end{array}$ & 2010 & $\begin{array}{l}\text { Educação Infantil - Universidade Cidade de } \\
\text { São Paulo (UNICID - 2013) } \\
\text { Ensino Lúdico - Faculdade São Luís - (2017) }\end{array}$ & Não \\
\hline Fernanda & $\begin{array}{l}\text { Magistério de } \\
\text { Nível Médio/ } \\
\text { Pedagogia } \\
\end{array}$ & UNISO & 1991 & Universidade Castelo Branco (UCB) & Não \\
\hline Juliana & Pedagogia & $\begin{array}{l}\text { Universidade do } \\
\text { Estado do Rio de } \\
\text { Janeiro (UERJ) } \\
\end{array}$ & 2002 & $\begin{array}{l}\text { Supervisão e Administração Escolar - Univer- } \\
\text { sidade Cândido Mendes (UCAM, RJ - 2003) }\end{array}$ & Curso de Letras - 2011 \\
\hline Antônia & Pedagogia & UNISO & 2005 & $\begin{array}{l}\text { Gestão em educação - Faculdade de Educa- } \\
\text { ção São Luís (2008); } \\
\text { Alfabetização e Letramento - FALC (2011). }\end{array}$ & $\begin{array}{l}\text { Letra e vida - } 2009 \\
\text { Formação de professores do pacto } \\
\text { pela alfabetização na idade certa } \\
\text { (2014) }\end{array}$ \\
\hline
\end{tabular}

Fonte: Dados de pesquisa (2019). 
Em termos de formação inicial, como consta no Quadro 2, verifica-se que há muitas semelhanças, pois seis se formaram em Pedagogia em cursos superiores de instituições privadas, e só dois em universidades públicas. Vale ressaltar que a lógica de ensino e a de formação desses espaços são muito diferentes, pois estão caracterizadas por propostas político-pedagógicas distintas. O ano de conclusão da graduação entre esses profissionais é disperso, a sinalizar que participaram de diferentes momentos da discussão curricular do curso de Pedagogia.

Todos os/as professores/as realizaram pós-graduação, mas apenas uma professora possui a titulação de doutorado em educação. Além do mais, a formação continuada desses profissionais não indica preocupação com a temática de gênero e sexualidade. O fato de a formação continuada apresentar temáticas tão distintas não aponta uma dispersão teoria-prática? O interesse por determinadas especializações ou cursos complementares tem em vista o aprofundamento teórico-prático ou apenas certificação, como Bourdieu (2019) aventou essa hipótese?

Quadro 3 - Tempo de experiência na docência dos participantes

\begin{tabular}{|c|c|c|}
\hline Participante & $\begin{array}{c}\text { Tempo de experiência na } \\
\text { Educação Básica }\end{array}$ & $\begin{array}{c}\text { Tempo de experiência na } \\
\text { Educação Infantil }\end{array}$ \\
\hline Maria & 11 a 15 anos & 1 a 3 anos \\
\hline Marisa & 11 a 15 anos & 7 a 10 anos \\
\hline Isabel & 11 a 15 anos & Não há \\
\hline Beto & 4 a 6 anos & 1 a 3 anos \\
\hline Ana Cláudia & 16 a 20 anos & 11 a 15 anos \\
\hline Márcia & 7 a 10 anos & 4 a 6 anos \\
\hline Fernanda & Acima de 21 anos & 1 a 3 anos \\
\hline Juliana & 7 a 10 anos & Não há \\
\hline Antônia & 11 a 15 anos & 1 a 3 anos \\
\hline
\end{tabular}

Fonte: Dados de pesquisa (2019).

Agora, em âmbito de experiência profissional, a maioria dos profissionais possui mais de dez anos na educação básica, porém o tempo na educação infantil representa em média três anos. Em geral, a maioria está há muito tempo na rede municipal. Será que a educação infantil é vista como uma escolaridade obrigatória e campo de atuação profissional? Ou uma assistência às crianças? 
Todos/as os/as docentes alegaram ser concursados. Sete dos nove professores ocupam o cargo de professores da rede de ensino e duas participantes ocupam os cargos de gestão escolar: vice-diretora e orientadora pedagógica.

A partir desse perfil profissional, Bourdieu (2019) nos instiga a problematizar sobre os aspectos da divisão dos cargos mediante as características atribuídas a homens: seria por esses aspectos que a educação é ocupada predominantemente por mulheres? Seria, então, uma área subalterna que deveria ser ocupada pelas mulheres, uma vez que elas possuem os requisitos necessários para cuidar de criança?

Após a realização dos questionários, selecionaram-se para a entrevista semiestruturada duas professoras formadas em Pedagogia com experiência na Educação Infantil, sendo que uma delas é gestora, ocupa o cargo de coordenadora pedagógica, mas, tendo também, anteriormente, desenvolvido um trabalho como docente nesta etapa de escolarização. Os participantes que foram escolhidos: Ana Cláudia e Marcela.

Ana Cláudia tem 35 anos, é casada e não tem filhos, e seu trabalho na instituição é de mediação e acompanhamento aos professores, dando suporte em sua prática pedagógica, além de estar ligada também aos pais.

Ao ser questionada, na posição de gestora, sobre como trabalha com questões de gênero, ela indica que o trabalho a ser realizado é diretamente com os professores e com os pais, trazendo essas diferenciações para a problematização e, nas ações aparentemente tão inofensivas, grandes questionamentos, como na separação dos brinquedos, diferenciação por cor etc. Para que sua ação seja concreta, estas questões estão presentes dentro do Projeto Político-Pedagógico da escola, de forma a visar a uma prática consciente do papel da educação, promovendo um poder e até mesmo, emancipação.

Como preleciona Louro (2014, p. 67),

O processo de "fabricação" dos sujeitos é continuado e geralmente muito sutil, quase imperceptível [...], nosso olhar deve se voltar especialmente para as práticas cotidianas em que se envolvem todos os sujeitos. São, pois, as práticas rotineiras e comuns, os gestos e as palavras banalizados que precisam se tornar alvos de atenção renovada, de questionamento e, em especial, de desconfiança. A tarefa mais urgente talvez seja exatamente essa: desconfiar do que é tomado como "natural". 
Em outro momento, ao ser questionada sobre a divisão das tarefas do lar e como lida com a sua dupla jornada, Ana Cláudia foi enfática:

Meu companheiro colabora bastante, ele entende que a casa é um contexto dos dois, então as atividades também são dos dois. Porém, mesmo com essa divisão, acaba que para mim ficam mais atividades. Acho que para mulher, pelo histórico, você não consegue chegar em casa, olhar e deixar de lado, você acaba fazendo mais coisas. É histórico isso também [risos].

Quando Ana Cláudia foi indagada sobre seu ambiente de trabalho predominantemente feminino e como as relações sociais eram estabelecidas pelas mulheres, a entrevista relatou que ela e as demais colegas enfrentam jornadas duplas de trabalho, motivo do qual elas se queixam regularmente no cotidiano escolar.

A coordenadora nos traz elementos de uma fala desconstruída, porém ainda inserida dentro de um aspecto patriarcal, na qual, historicamente, o domínio da esfera privada era das mulheres, sem direito à participação da vida civil. E, ao analisar a fala sobre seu ambiente de trabalho, nota-se o aspecto da inserção feminina na vida civil - esfera pública - por meio do trabalho, mas ainda se sobressaem fortes características da vida privada, devido às responsabilidades familiares e domésticas. De acordo com Senkevics (2011), dados referentes ao ano de 2007 indicavam que, entre os profissionais da docência na creche, 97,9\% eram mulheres, índice reduzido a $74,4 \%$ no ensino fundamental e a $64,4 \%$ no ensino médio, enquanto no ensino superior $45 \%$ do corpo docente era composto por mulheres.

Segundo Maruani (1992), existe a "segregação horizontal" (dentro da própria profissão) e a "segregação vertical", que se referem às dificuldades das mulheres de alcançar altos postos de hierarquia profissional. Segregações dessa ordem são identificadas na literatura pelo termo "teto de vidro" (PRÁ; CEGATTI, 2016, p. 223). Tais dificuldades podem ser atribuídas às tarefas do lar, que insistem em recair somente às mulheres e, até mesmo, sobre atividades que não são vistas como "coisas de mulher". Isso se contradiz ao homem que possui liberdade e nenhum compromisso a mais, permitindo seu aperfeiçoamento profissional, dedicando-se exclusivamente aos estudos.

Em outro momento da entrevista, foi lançada uma pergunta relacionada ao magistério, questionando-a se, em algum momento, sentiu que características exclusivamente femininas influenciaram sua prática docente e como se enxergava enquanto mulher dentro da sociedade atual. 
Acho que o que influenciou, em alguns momentos, eu não sou mãe. Então por exemplo, já fui por várias vezes questionada de estar na escola e falar sobre a educação de crianças, não sendo mãe. E isso pegou para mim, do tipo: "como que você está falando se você não sabe como é educar?". Então quando eu vou falar com as mães, elas me perguntam: "Você tem filho? Você sabe como é difícil?" E eu sempre tento falar para elas que eu estou num lugar profissional, não é um lugar do senso comum, cotidiano da família, mas é um pouco complicado. Agora ser mulher na sociedade, ainda é um grande desafio. Nós já conquistamos muitas questões, mas eu sinto que por ser mulher, muitas outras questões são bem complexas, que se tivesse no lugar de homem, não seria. (Ana Cláudia).

Quando crianças, inseridas dentro do contexto da educação básica, independentemente do financiamento ser municipal ou privado, o que os pais e a sociedade esperam dos professores? É realmente a busca pela educação de qualidade, como objetivo principal o desenvolvimento deste indivíduo, em aspectos cognitivos, sociais e psicológicos, ou simplesmente os cuidados básicos, suprindo determinadas necessidades e tampando lacunas ao longo do seu crescimento? 0 ser humano como ser histórico carrega nuances que pouco percebemos, devido a uma certa cultura já naturalizada, e dessa forma, ao remeter o sentido familiar do que é ser professor, como se fosse uma vocação, quando não visto como sacerdócio.

Tendo presente o contexto histórico de assistencialismo da educação infantil, Ana Cláudia foi questionada sobre como enxerga o indissociável cuidar e educar, trazendo em sua resposta elementos fundamentais, como a função real da escola na vida dos sujeitos e sua constituição.

Eu penso que são duas questões intrínsecas, mas que a gente tem que ter um cuidado principalmente na educação infantil, de não retornar àquele aspecto assistencialista que foi inicialmente, tem essa questão do cuidado, afeto, das questões cotidianas da escola, mas saber que a função principal da escola é a educação, é a apropriação dos conhecimentos e isso vai fazer a diferença depois na constituição dessas pessoas, acho que isso é o foco da escola. (Ana Cláudia).

Posteriormente, a entrevista semiestruturada foi aplicada a Marcela, uma professora da educação infantil, que leciona para alunos de cinco anos; casada há um ano e sem filhos. Ao ser questionada sobre se trabalha questões de gênero em sala, quais atividades promove e quais questionamentos levantados, pôde-se per- 
ceber um trabalho diferente daquele descrito por Ana Cláudia. Essa diferença se dá pelo fato das distintas posições que ambas assumem. Enquanto uma, desenvolve uma ação efetiva com os pais e professores, e Marcela atua diretamente com os alunos, em suas práticas cotidianas do dia a dia. Aqui, implicitamente, nota-se a importância de um trabalho em equipe, na qual uma atividade reflete em outra.

Então, eu costumo trabalhar muito com a autonomia, conhecimento do próprio corpo, com o gênero em si, não; principalmente no faz-de-conta. A gente procura deixar eles livres [...]. Até teve um momento esses dias, que nós o levamos em uma sala da nossa escola que a rotulamos como "cantos", e um menininho falou assim: "aí, lá eu não vou... porque é de casinha, é de menina". Aí, nós falamos: "não, não é de menina, os meninos também brincam de casinha". "Mas, eu posso ser o filho?" "Claro, você pode ser o que você quiser." E, quando nós vimos, ele já estava brincando [...]. Então, a gente costuma entrar e fazer com que eles participem de todos os momentos, e nesses momentos que nós fazemos essa interação, a mediação. Dessa forma, na sala, a gente trabalha muito o corpo, deles se reconhecerem, dessa autonomia, de saber desenhar o corpinho, quais as partes do corpo etc., mas o gênero em si, não. (Marcela).

O relato de Marcela evidencia a preocupação com o desenvolvimento integral das crianças, estimulando, principalmente, a criatividade, imaginação, interações e recorrendo a ferramentas fundamentais nesse processo de construção, isto é, o trabalho pedagógico pelo lúdico. "O lúdico influencia enormemente o desenvolvimento da criança. É através do jogo que a criança aprende a agir, sua curiosidade é estimulada, adquire iniciativa e autoconfiança, proporciona o desenvolvimento da linguagem, do pensamento e da concentração" (VYGOTSKY, 1998).

Vygotsky (1998) postula que, ao reproduzir o comportamento social do adulto em seus jogos, a criança está combinando situações reais com elementos de sua ação fantasiosa. Esta fantasia surge da necessidade da criança, como já dissemos, em reproduzir o cotidiano da vida do adulto da qual ela ainda não pode participar ativamente. Porém essa reprodução necessita de conhecimentos prévios da realidade exterior, deste modo, quanto mais rica for a experiência humana, maior será o material disponível para as imaginações que irão se materializar em seus jogos. A construção do real parte então do social (da interação com outros), quando a criança imita o adulto e é orientada por ele, e paulatinamente é internalizada pela criança. Ela começa com uma situação imaginária, que é uma reprodução da situação real, sendo que a brincadeira é muito mais a lembrança de 
alguma coisa que de fato aconteceu, do que uma situação imaginária totalmente nova. Conforme a brincadeira vai se desenvolvendo, acontece uma aproximação com a realização consciente do seu propósito. Portanto, fazendo uma conexão com esse pensamento, a criança não carrega preconceitos nem estereótipos, mas apropria-se do seu meio e reproduz isso em suas ações. O papel de mediação da professora Marcela fez total sentido no momento de negação do menino ao brincar de casinha, demonstrando que esse comportamento faz parte do cotidiano de muitos, sendo cultura do patriarcado e da construção histórica dos sujeitos. Todavia a temática "gênero" não é trabalhada pela professora como um componente obrigatório. Será que a invisibilidade dessa discussão não contribui para reforçar os estereótipos ou pseudoeducação igualitária?

Em seguida, ao ser questionada sobre sua dupla jornada, Marcela foi enfática ao dizer que é difícil, pois realiza dupla jornada e está casada. Inclusive, o ponto principal presente na fala de Marcela e da Ana Cláudia é jornada dupla de trabaIho que as professoras precisam realizar por diferentes motivos que nos levam a questionar se isto não se configura precarização do trabalho docente, ainda mais pela sua condição social, política e de gênero. Em termos de lei, o Estatuto dos Servidores Municipais (SOROCABA, 1991) possibilita que o/a professor/a trabalhe em período oposto da rede municipal, inclusive em cidades vizinhas.

Ainda falando em termos de concurso, Marcela foi questionada sobre como ela sentia as relações femininas em seu ambiente de trabalho. Ela fez um paralelo entre escolas municipais e privadas, visto que possui experiências em ambas. 0 que se pode notar em sua fala é uma relação de competição, mas oriunda do sistema econômico e político em que estamos inseridos.

Isso é complicado. Isso é difícil. Eu já trabalhei tanto no particular quanto na municipal. Na municipal, por todas serem concursadas, todas terem entrado da mesma forma, por não haver uma competição entre nós para ver, por exemplo, quem vai subir de cargo, a gente acaba ficando mais à vontade. Mesmo assim, eu acho que algumas escolas fortalecem isso: "Porque fulano fez isso, porque fulano fez aquilo..." e a própria escola acaba criando esse conflito entre uma e outra. Porque mulher tem muito disso, "de hormônio", as vezes você não está bem, não está legal, e eu acho que, não são todas, mas algumas escolas acabam criando esse conflito entre nós, professoras municipais. E, ao contrário de uma escola particular, por exemplo, que elas brigam por um cargo melhor. Você sabe, se você for bom, você terá um cargo melhor, e fica aquela briga. E na municipal não tem isso, todo mundo entrou 
do mesmo jeito, todo mundo fez a mesma prova, para virar diretora tem que fazer uma prova de novo. Acho que a escola em que você trabalha que acaba fazendo isso. Eu não vejo muito isso, mas eu sei que tem por aí. (Marcela).

A diferença apresentada por Marcela remete à regulação do trabalho: serviço público versus privado (regime CLT). Tal diferenciação merece aprofundamento em outras investigações. A partir do objetivo desta pesquisa, problematiza-se o termo "hormônio feminino" e a relação interpessoal no trabalho. O senso comum traça o perfil de que ser mulher é um "problema biológico". As dificuldades travadas no interior das relações sociais num grupo de mulheres corresponderiam ao seu sexo biológico e/ou identidade feminina. Ao mesmo tempo, o trabalho na educação infantil deveria ser ocupado por mulheres, porque a identidade masculina não propiciaria viver em um ambiente organizado. Bourdieu (2019) esclarece que diferença entre homem e mulher está socialmente construída, mas a diferença anatômica torna-se o fundamento e a caução aparentemente natural da visão social que a alicerça.

De antemão, pode-se questionar: se o funcionalismo público atende a todos, por que no magistério a presença é predominantemente feminina? Quando Marcela foi questionada sobre a ausência de homens na educação infantil, sua resposta foi incisiva.

Como já disse antes, elas entendem que aqui é extensão da casa e que eu por ser mulher já tenho mais um "jeito", por ter filho, por ter nascido assim, com essa "maternidade". E elas ficam muito assim com homem em relação ao banheiro. "Eu tenho uma filha mulher, uma menina, aí, mas vai ser professor homem que vai levar ao banheiro?" Elas não conseguem enxergar os professores como profissionais em pedagogia, como pedagogas(os). Ela enxerga a professora como mulher e o professor como homem, elas veem pelo gênero e não pelo profissional. É um pouco difícil, mas elas vão se acostumando com o tempo... Tem professores que são ótimos, e que elas (mães) acabam adorando depois, mas, a primeira impressão é "aí, mas é um homem?" "Poxa, é um homem que vai ficar com a minha filha de três anos?" "Mas é um homem que vai levá-los ao banheiro?" E a mulher não tem isso [...]. A mulher é mãe, a mulher não vai fazer, a mulher cuida. (Marcela).

Aqui, há uma fala fortemente relacionada à construção do gênero masculino e feminino e o quanto há impactos na educação. A perspectiva de educação, desde os primórdios, mostrou-se como privilégio de poucos. A história, principalmente, a partir da matriz judaico-cristã, é balizada na supremacia do homem e a sujeição 
das mulheres aos cuidados do lar e às vontades de seus companheiros (LOURO, 2014; PRÁ; CEGATTI, 2016; DIAS; CRUZ, 2015; BOURDIEU, 2019).

As características atribuídas exclusivamente ao feminino, como a de ser mãe, educadora de filhos, religiosa, estendem-se até o seu ingresso na busca por profissionalização na área da docência, pois tais determinações já estavam e estão enraizadas na sociedade. Com a abertura do magistério para as mulheres, suas qualidades profissionais se tornaram limitadas, ressaltando seu papel feminino, como um suposto "dom" de mediar o comportamento emocional e moral das crianças. Esse "dom" explica-se pelo poder da mulher de gerar um indivíduo, "consequente função materna", de cuidar e educar crianças, tornando essa característica fruto da feminilidade, transformando a profissão em uma missão feminina, já que educar e socializar os sujeitos durante a infância era uma "vocação" exclusiva das mulheres (LOURO, 2014; BOURDIEU, 2019).

Todavia ainda parece que os legisladores objetivam recuperar essa visão sexista e cis gênero na educação. Três deputadas estaduais de São Paulo, do Partido Socialista Liberal - Janaina Paschoal, Leticia Aguiar, Valeria Bolsonaro -, entraram com o Projeto de Lei 1.174/2019, com a proposta de reconhecer por lei que profissionais do sexo feminino tenham a exclusividade nos cuidados íntimos com crianças na Educação Infantil. O artigo 1ㅇ do projeto de lei estabelece que "Na Educação Infantil, os cuidados íntimos com as crianças, com destaque para banhos, trocas de fraldas e roupas, bem como auxílio para usar o banheiro, serão realizados exclusivamente por profissionais do sexo feminino" (SÃO PAULO, 2019). Tal projeto reforça o desconhecimento dos aspectos históricos, filosóficos e sociológicos que permeiam a constituição da docência na educação.

Com base nos dados da pesquisa e da literatura, pode-se afirmar que a educação e a construção do gênero resultam em um homem provedor financeiro da família, trabalhando fora e adentrando ambientes tido como masculinos. Segundo Rabelo e Martins (2010), as representações sociais apontam que as profissões ligadas à emoção, ao afeto e à sensibilidade são entendidas como espaços das mulheres, enquanto aquelas relacionadas à razão, à inteligência e à força são tomadas como apropriadas aos homens.

Não podemos deixar de sublinhar que esses encaminhamentos sociais e culturais produzem e são produzidos em meio a discursos e representações que buscam afirmar e reafirmar estereótipos culturais, os quais fixam, 
em determinados papéis e funções, os lugares de homens e de mulheres. Especificamente, a Educação Infantil busca se firmar e se manter como uma profissão de mulheres, ancorando as suas justificativas em noções biologicistas, as quais afirmam que as mulheres são, por natureza, mais delicadas, dóceis e aptas ao cuidado de crianças do que os homens. Esses, por sua vez, são representados pela virilidade, força e coragem, atributos desnecessários à educação e ao zelo por crianças. (JAEGER; JACQUES, 2017, p. 546.

Conforme os estudos (OLIVEIRA, 2011; LOURO, 2014; DIAS; CRUZ, 2015; PRÁ; CEGATTI, 2016) e os resultados de estudo, evidencia-se que educação infantil tem tido como característica o cuidar, eximindo-se do educar, demonstrando que esse papel cabe somente às mulheres, pois estas, sim, possuem capacidade de afeto, cuidado e educação, entretanto, não aquele caráter de apropriação do conhecimento, mas ressaltando o aspecto maternal. É comum enxergarem a professora como uma mãe, e a escola, como extensão de casa. Origina-se, assim, a estranheza da presença masculina na educação infantil, já que, historicamente, não cabe aos homens a educação, o cuidado e as atribuições que seriam ofícios de uma casa.

Analisando as falas das entrevistadas e todo o estudo desenvolvido ao longo desta pesquisa, Bourdieu (2019) nos propicia respaldo para compreender que a construção histórica de gênero é também responsável pela divisão sexual do trabalho. O autor volta ao aspecto biológico, dizendo que ser homem ou mulher acontece distante de tal característica, mas que isso acontece como um "regulador" para a visão androcêntrica do mundo, ou seja, há espaço naturalmente feminino e masculino.

\section{CONCLUSÃO}

O presente estudo demonstra que há uma construção histórica do que é ser homem e mulher e o quanto estes indivíduos são afetados por essa condição. Homem e mulher sofrem diariamente estigmas impostos por uma cultura repressiva, que afeta a todos, inclusive a educação - em especial, a infantil. O espaço predominantemente feminino traz significados velados, como se características requeridas para a docência não fossem estritamente profissionais, mas sim maternais. Isso é consequência do fenômeno cuidar e educar, intrínseco da educação infantil, em que, às vezes, acabam prevalecendo os cuidados. 
O trabalho com gênero deve ser discutido a todo momento e no coletivo, principalmente dentro das escolas, buscando práticas igualitárias, coerentes, livres e justas, de forma a demonstrar, ainda, que é possível garantir que o papel da escola, de propiciadora de conhecimentos e de mudanças sociais, seja efetivo. Por isso, ressalta-se a importância de se trabalhar questões relacionadas a gênero com crianças, objetivando desconstruir a perspectiva androcêntrica.

Portanto o presente trabalho visa propiciar reflexões e também subsídios teóricos para os Estudos de Gênero, além de fomentar discussões em escolas, universidades e formulação de políticas públicas que visem à igualdade, liberdade e, principalmente, à valorização profissional do/da pedagogo/pedagoga, buscando a quebra do patriarcado e a inserção da mulher em todas as áreas que desejar.

\section{REFERÊNCIAS}

BOURDIEU, P. A dominação masculina: a condição feminina e a violência simbólica. Tradução de Maria Helena Kühner. 15. ed. Rio de Janeiro: Bertrand Brasil, 2019.

BRASIL. Ministério da Educação. Instituto Nacional de Estudos e Pesquisas Educacionais Anísio Teixeira. Senso escolar 2017 - notas estatísticas. Brasília, DF: INEP, 2018. Disponível em: https://download.inep.gov.br/educacao_basica/censo_escolar/notas estatisticas/2018/notas_estatisticas_Censo_Escolar_2017.pdf. Acesso em: 25 mar. 2018.

CHAER, G.; DINIZ, R. R. P.; RIBEIRO, E. A. A técnica do questionário na pesquisa educacional. Evidências, Araxá, v. 7, n. 7, p. 251-66, 2011.

MANZINI, E. J. Entrevista semiestruturada: análise de objetivos e de roteiros. In: SEMINÁRIO NACIONAL SOBRE PESQUISA E ESTUDOS QUALITATIVOS, 2., 2004, Bauru. A pesquisa qualitativa em debate. Anais [...]. Bauru: USC, 2004.

DIAS, A. F.; CRUZ, M. H. S. (Org.). Educação e igualdade de gênero. Jundiaí: Paco Editorial, 2015.

ESTEBAN, M. P. S. Pesquisa qualitativa em Educação. Porto Alegre: AMGH, 2010.

INSTITUTO BRASILEIRO DE GEOGRAFIA E ESTATÍSTICA. Base de dados populacional de Sorocaba. Portal IBGE, Rio de janeiro, 2017. Disponível em: https://cidades.ibge.gov.br/ brasil/sp/sorocaba/pesquisa/23/25207?tipo=ranking\&indicador=25189. Acesso em: 25 mar. 2018. 
JAEGER, A. A.; JACQUES, K. Masculinidades e docência na educação infantil. Revistas Estudos Feministas, Florianópolis, v. 25, n. 2, p. 545-70, ago. 2017. Disponível em http:// www.scielo.br/scielo.php?script=sci_arttext\&pid=S0104-026X2017000200545\&lng=pt\& nrm=iso. Acesso em: 27 abr. 2019.

LOURO, G. L. Gênero, sexualidade e educação: uma perspectiva pós-estruturalista. 16. ed. Petrópolis, RJ: Vozes, 2014.

MARUANI, M. As mulheres no mercado de trabalho: tendências e evoluções nos doze países da Comunidade Europeia. Cadernos de Mulheres da Europa - Comissão das Comunidades Europeias, [s.l.], n. 36, p. 1-21, mar. 1992.

MINAYO, M. C. S; ASSIS, S. G; SOUZA, E. R. (Org.). Avaliação por triangulação de métodos: abordagem de programas sociais. Salvador: EDUFBA; Rio de Janeiro: Editora Fiocruz, 2005.

OLIVEIRA, Z. M. R. Educação infantil: fundamentos e métodos. 7. ed. São Paulo: Cortez, 2011.

PESSOA, Larissa. Na educação infantil, a cada 40 docentes só um é homem. Cruzeiro do Sul, Sorocaba, 11 de maio de 2018. Disponível em: https://www2.jornalcruzeiro.com. $\mathrm{br} / \mathrm{materia} / 885128 /$ na-educacao-infantil-a-cada-40-docentes-so-um-e-homem. Acesso em: 16 ago. 2019.

PRÁ, J. R.; CEGATTI, A. C. Gênero, educação das mulheres e feminização do magistério no ensino básico. Retratos da escola, Brasília, v. 10, n. 18, p. 215-28, jan./jun. 2016.

RABELO, A. O.; MARTINS, A. M. A mulher no magistério: um histórico sobre a feminização do magistério. In: CONGRESSO LUSO-BRASILEIRO DE HISTÓRIA DA EDUCAÇÃO, 6., 2010, Uberlândia. Anais [...]. Uberlância: PUC-RJ / UFU / Unesp / UFPR / Universidade do Minho / Universidade de Lisboa, 2010. p. 6167-76.

SÁ, C. M.; ROSA, W. M. A história da feminização do magistério no Brasil: uma revisão bibliográfica. In: CONGRESSO BRASILEIRO DE HISTÓRIA DA EDUCAÇÃO, 3., Educação escolar em perspectiva histórica. 2004, Curitiba. Anais [...]. Curitiba: PUCPR, 2004.

SÃO PAULO (Cidade). Projeto de Lei 1174/2009, de 16 de outubro de 2019. Confere às profissionais do sexo feminino exclusividade nos cuidados íntimos com crianças na Educação Infantil. São Paulo: Assembleia Legislativa, 2019. Disponível em: https://www. al.sp.gov.br/propositura/?id=1000292074. Acesso em: 23 out. 2019.

SENKEVICS, A. A feminização do magistério: considerações iniciais. Ensaios de gênero, 05 dez. 2011. Disponível em: https://ensaiosdegenero.wordpress.com/2011/12/05/afeminizacao-do-magisterio. Acesso em: 10 mar. 2016. 
SOROCABA (Cidade). Lei n. 3800, de 2 de novembro de 1991. Dispõe sobre o estatuto dos Servidores Públicos Municipais de Sorocaba e dá outras providências. Sorocaba: Câmara Municipal, 1991. Disponível em: https://camara-municipal-da-sorocaba.jusbrasil.com.br/ legislacao/539999/lei-3800-91\#art-2--inc-VII. Acesso em: 19 ago. 2019.

VYGOTSKY, L. S. A formação social da mente. São Paulo: Martins Fontes, 1998.

\section{Sobre os autores:}

Rafaela de Souza Lima: Graduada em Pedagogia pela Universidade Paulista (UNIP), campus Sorocaba. Pedagoga na Rede Municipal de Ensino de Sorocaba, SP. E-mail: rafaela.sirino@hotmail.com, Orcid: http://orcid.org/0000-0001-9250-7498

João Henrique da Silva: Doutor em Educação Especial pela Universidade Federal de São Carlos (UFSCar). Mestre em Educação pela Universidade Federal da Grande Dourados (UFGD). Filósofo e pedagogo. Professor Adjunto do Programa de Pós-Graduação em Educação da Universidade Tuiuti do Paraná (UTP). E-mail: jhsilvamg@icloud.com, Orcid: http://orcid.org/0000-0003-0277-0466

\section{Recebido em: 11/01/2020}

Aprovado em: 08/05/2021 